\title{
Relation of locus of control and creativity with learning styles
}

\author{
Ramazan Hamdi ${ }^{1}$, Farzad Pourheidari ${ }^{2}$, Nematulla Moradi ${ }^{2}$ \\ 1. M.A, Department of Educational psychology, Science and Research Branch, Islamic Azad \\ University, Hamedan, Iran \\ 2. M.A, Department of Educational psychology, Science and Research Branch, Islamic Azad \\ University, Tehran, Iran \\ *Email:fa.pourheidari@gmail.com
}

\begin{abstract}
The current paper aimed to investigate the relation between the locus of control and creativity with learning styles among the third grade high school students in the city of Kamyaran. The universe under study in this research consisted of all third grade high school students of the city of Kamyaran. The statistical population included 300 third grade students who were chosen by the cluster sampling method. Tools for collecting data involved the Abedi's creativity questionnaire (1993), Rotter's internal and external locus of control scale (1996) and the Kolb's learning styles questionnaire (1971). To analyze the data, the independent groups $t$ test, one-way variance analysis (ANOVA), the simple Pearson correlation and the multivariate variance analysis (MANOVA) were sued. Results indicated that there was a difference between students and the internal and external locus of control in terms of various learning styles $(\mathrm{P}<0 / 03)$, and also there was a difference between the students with the various learning styles and the creativity level $(\mathrm{P}<0 / 01)$. Findings also suggested that there was a significant difference between the internal and external locus of control with the creativity and gender, and also there was not a significant difference between learning styles and gender.
\end{abstract}

Keywords: Locus of control, Creativity, Learning styles

\section{Introduction}

If we take a look at the lives of humans and animals in the faraway past, we'll find out that the animals back in thousands of years ago have not made any difference as compared with today. Their way of life is the same as it was 5-10 years ago. However, in prehistory periods of time when humans used to employ stones and wood for defending themselves and dwell in case and over trees like animals saw various transformations during life, such that today man has attained some astonishing developments and advancements that no one could have imagined in the past centuries (Parsa, 2007). If a living creature fails to learn which objects are safe and which are dangerous, he will be eliminated soon. He also has to learn how to behave so as to gain positive stimuli and avoid negative stimuli (Hergenhan and Olson, 2009; Trans by Seif, 2010). What we know is not already taught. We inherit some capacities-i.e. they are innate and inborn not learnable. Therefore, one of the most important social progresses in human life is learning, the child at the beginning comes to the world with some instinctive and physiological capacities, then, besides instinctive and natural capacities like growth and reflections, that which makes up his character is an outcome of his learning (Karimi, 2010). That which has in recent years attracted the attention of educational psychologistst and experts has been the variety of learning styles, thinking, strategies and learning strategies and study (Seif, 2008).

Guilford (1962) announced that a creative action is a sign of learning, so any perfect learning theory should place special emphasis on creativity. Learning has a main role in 
peoples' survival and various definitions are provided for it, however, a definition (Kimbel, 1961) presented for learning is among the most famous definitions. He states learning is some relatively stable changes to the behavioral capacity (potential behavior) which occurs as a result of reinforced practice and does not include temporary states of the body like that which appears because of illness, fatigue, and drugs (Quoted by Seif, 2008).Most psychologists have considered years after the 1950s as " a new cognitive revolution", because new journals and expert groups as psychologists had increasingly turned to the cognitive psychology (Solso, 2009; Trans by Maher, 2009). The new cognitive revolution has had a deep impact on intelligence conceptualization ways and personality. Concerning personality studies in terms of a cognitive perspective, a series of individual differences is raised which are to be addressed as cognitive styles (Dashti, 2006). Fetsko and McKlor defined the cognitive style principally as a way by which the learner processes the information (Quoted by Seif, 2008). This concept is applied as a complementary input behavior and is a another contributing factor to the assumed learning of the learning style (Decheko and Crawford, 1974; quoted by Seif, 2008). Learning styles can be divided into three cognitive, affective and physiological categories (Quoted y Seif, 2008). Cognitive learning styles are relatively stable manners through which people receive and process the information and organize it. (Hun, 1995). Kolb (1984) states one of the cognitive styles is learning styles which is divided into four parts and these styles correspond with a pattern of learning process. In this pattern learning is conceived of a four stage cycle: concrete experience, reflective observation, abstract conceptualization and active experimentation. Kolb and Ferrai (1975), given the learning pattern introduced two dimensions and four learning styles. The first dimension includes two learning styles of concrete experience versus abstract conceptualization. The second dimension to include two learning styles of active experimentation versus reflective observation (Quoted by Seif, 2008).

Kolb, by combining the four mentioned learning styles named the four style of learning. These learning styles are convergent learning style, divergent learning style, assimilator learning style, and accommodator learning style (Quoted by Seif, 2008). Creativity is one of the human cognitive capacities which is consistently influenced by his cognitive style. Creativity is a type of divergent thinking, where there is no decisive answer while there might be various possible answers; each of which might be true rationally. (Quoted by Seif, 2008). Torrens and Gaffe (1989) quoted by Sheikholeslami and Razavi (2005) consider a creative thinking as consisting of four main factors: 1. Fluidity (talent for producing many ideas), 2. Extension (talent for producing innovative, unusual and new ideas), 3.Innitiative (talent for producing ideas and various ways) and 4 . Flexibility (talent for attention to details).

Rogers (1995) has introduced one of the cognitive styles as "the internal locus of control versus the external locus of control" (Quoted by Dashti, 2006). Rotter (1972) states that people who are specified with the variable of internal locus of control personality maintain the reinforcement they receive is under their own behaviors and characteristics. Those with external locus of control conceive the reinforcement is controlled by others, destiny and chance. They are convinced that are incapable against these external forces. Researches have been conducted inside and outside of the country in the area of comparing learning styles, creativity and locus of control have reaffirmed relationship between them. Dashti (2006) in a research addressed the relationship of cognitive learning styles, creativity and locus of control among the students which indicated that there was a significant difference between learning styles and locus of control. Boostan (2003) in study delved into the relationship of the locus of control and creativity among the students at the Sanati Sharif University where the findings revealed a positive relationship between the two variables. Instructors mostly due to convenience and mastery over educational styles relating to themselves are more inclined 
toward more education with the previous styles (Young, 2007). The significance of nurturing the creativity of the next generation is constantly on the rise. Maybe, having an educational degree in the past for finding a job was enough, but today conditions are tight and companies and organizations are looking for people who in addition to the classic knowledge possess some creativity and tangible abilities (general and specialized). The conditions of tomorrow's world will be ever harder and hence we have to pay more attention to raising creativity in our own children (Behjoya, 2009).

In the learning process, if controllable factors like "efforts" are emphasized it will engender in an encouragement for fulfilling assignments, perseverance and better performance; but emphasis on controllable factors like: ability, disposition, assignment difficulty and chance will increase anxiety and reduce efforts. Teachers can help students to comprehend their own affective reactions towards success and failure. Students who after failure expose special attributions from themselves experience special affective reactions too. Teachers and parents by helping the learners in comprehending their affective reactions towards success and failure help them to trade these feeling for a change in direction in the attributive thinking. Since, most adolscents in facing various life conditions particularly I educational situations interpret with adverse attributions their own success and failures, understanding and determining these attributions and changing adverse attributions among the students for success will be fruitful (Spalding, 1998; quoted by Ebrahimi, 2007).

\section{Research hypotheses}

1. There is a difference among students with the internal and external locus of control in terms of learning styles.

2. There is a difference among students with the internal and external locus of control in terms of creativity.

3. There is a difference among students with various learning styles in terms of creativity.

\section{Methodology}

The present paper is descriptive and of a correlation type. Correlation researches are employed for describing and predicting and discovering the relationships between two or more variables. The statistical population of this research included all the third grade students of the city of Kamyaran in the 2011-2012. The selected sample for the research involved 300 third grade students. To choose the sample in question the cluster sampling method was applied. Thus, first 5 girl schools and 6 boy schools were selected and then from each school one class were chosen randomly. The tools employed in this research are:

\section{Learning styles questionnaire}

This questionnaire was developed by Kolb (1971) for measuring learning styles and each part measures a type of ability. This questionnaire has 12 questions and each question includes four parts and the subject should answer them within 15 minutes. The subject by reading any question should give score 4 to any part which most corresponds to his learning quality and then specify the score for each question by 1, 2, 3 and 4 (Kolb, 1984). Various parts of this test are concrete experience (CE), reflective observation (RO), abstract conceptualization (AC) and active experimentation (AE). This scale includes 12 questions and each question includes four parts; $\mathrm{CE}, \mathrm{RO}, \mathrm{AC}$ and $\mathrm{AE}$ respectively. By adding up these 
four parts, four scores are obtained that indicate four learning styles. Of subtraction of two by two of the above parts, i.e. subtracting AC from RO two scores is achieved. These two scores are placed on two axes of coordinate, i.e. the vertical axis (AC-CE) and horizontal axis (AE-RO). These two axes of the coordinate constitute four quadrants of a square which correspond with four divergent, convergent, accommodator and assimilator learning styles. In this tool questions 1-6 measure the concrete experience and abstract conceptualization while questions 7-12 evaluate reflective observation and active experimentation of the students. In this questionnaire, the highest score acquired by the students in abstract conceptualization and active experimentation (convergent learning style), the highest score in the concrete experience and reflective observation (divergent learning style) and the highest score acquired in abstract conceptualization and reflective observation (assimilator learning style) while the highest score are interpreted in the concrete experience and active experimentation (accommodator learning style). The face validity of this test in the most recent research by Wilcoxon (1995) was investigated that indicated a good validity which is suitable for measuring learning styles (Wilcoxon, 1995). Using the Cronbach's alpha, Wilcoxon attained a reliability coefficient of $\mathrm{AE}=0 / 87, \mathrm{AC}=0 / 83, \mathrm{RO}=0 / 81$ and $\mathrm{CE}=0 / 82$, indicating a higher test credibility. In the research, to obtain reliability, the Cronbach's alpha method, split half and Spearman Brown methods were applied where the results (in accordance with the three above methods) for the concrete experience learning style were $(0 / 65,0 / 64,0 / 61)$, reflective observation $(0 / 51,0 / 44,0 / 44)$, abstract thinking $(0 / 61,0 / 57,0 / 57)$, active experimentation $(0 / 62,0 / 55,0 / 55)$ respectively.

\section{Creativity questionnaire}

This test which was developed by Abedi in 1993 based on the Torrens' theory about creativity in 1984 has 60 three choice questions to which scores from 1-3 are given. This test is consisted of four subtests of fluidity, extension, initiative and flexibility. Choices indicate low, middle and high levels of creativity, where score 1 is for low creativity, scores 2 and 3 are for middle and high creativity levels respectively. An aggregate of scores acquired in each subtest represents the subject's score in each part and an aggregate of subject's scores in the four subtests shows his overall creativity score. The overall creativity score of each subject ranges from 60 to 180 . Questions 1-22 relate to fluidity, 23-33 relate to extension, 34-49 relate to initiative while questions 50-60 relate to flexibility (Daemi et al, 2000). The internal consistency coefficient by using the Cronbach's alpha for the fluidity, flexibility, initiative and extension subtests on 2270 Spanish students were 0/75, 0/66, 0/61 and 0/61 respectively. To obtain validity, in the current paper the concurrent validity was used, where its coefficients for the fluidity, extension, initiative and flexibility subscales were $0 / 41,0 / 53$, $0 / 58$ and $0 / 60$ respectively being significant at the $0 / 01$ level. The reliability of the creativity test by Abedi was achieved through a retest on junior school students in Tehran in 1984 in four parts of the test which is as follow: reliability coefficients for the fluidity, initiative, flexibility and extension were $0 / 85,0 / 82,0 / 84$ and $0 / 80$ respectively. In the current paper, to attain the reliability, the Cronbach' alpha, split half and Spearman Brown methods were applied where the results for the subscales of fluidity were $(0 / 69,0 / 69,0 / 69)$, of extension $(0 / 54,0 / 52,0 / 52)$, of initiative $(0 / 70,0 / 77,0 / 77)$ and of flexibility $(0 / 57,0 / 57,0 / 57)$ and of the total questionnaire $(0 / 84,0 / 71,0 / 71)$ respectively. 


\section{Rotter's locus of control questionnaire}

Rotter (1996) prepared a scale to determine the peoples' internal and external locus of control without considering intelligence and gender. The scale was aimed to investigate the effects of the main social events on people. It has 29 items, hence out of the 29 items 23 items measure the internal and external locus of control and another 6 items, i.e. $(1,8,14,19$, 24 and 27) were planned for hiding the objective of the questionnaire. The Rotter's locus of control test scoring is such that a score is given to questions $3,4,5,10,11,12,13,15,22,26,28$ should choice "b" is selected while another score is given to questions $2,6,7,9,16,17,18,20$, $21,23,25,29$ when choice "a" is selected. The overall score acquired for the range of scale scores varies from 0-23. A higher score in this scale indicates an external orientation (external locus of control) and low score indicates internal orientation (internal locus of control). Franklin (1996) did a factorial analysis on the scores of 1000 people and found that all the questions are significantly correlated with a specific total factor and this factor was used to estimate around \%53 of the total variance. (Biabangard, quoted by Kakavand, 2002). For this, the Novick-Strickland scale was employed as the criterion for that case. The validity obtained is $0 / 039$. In the current paper, to obtain the questionnaire validity, the concurrent validity method was applied where the coefficient was $0 / 48$, being significant at the $0 / 01$ level. The reliability and credibility of tis scale in cross cultural researches were reported to be satisfactory. People receiving a score higher than 9 in this test has an external locus of control (Rasooli and Farahbakhsh, 2009).

\section{Findings}

Some of the descriptive indices, including average, standard deviation, and the highest and lowest scores of the research variables are presented on table (1).

Table 1. Descriptive indices of the research variables

\begin{tabular}{|c|c|c|c|c|}
\hline Index & Average & $\begin{array}{c}\text { Standard } \\
\text { deviation }\end{array}$ & $\begin{array}{c}\text { Highest } \\
\text { score }\end{array}$ & Lowest score \\
\hline Variable & $10 / 27$ & $3 / 64$ & 19 & 1 \\
\hline Locus of control & $59 / 32$ & $6 / 74$ & 83 & 43 \\
\hline Accommodator learning style & $61 / 74$ & $6 / 94$ & 85 & 43 \\
\hline Assimilator learning style & $60 / 37$ & $8 / 14$ & 84 & 39 \\
\hline Convergent learning style & $57 / 69$ & $7 / 89$ & 81 & 36 \\
\hline Divergent learning style & $27 / 48$ & 6 & 44 & 12 \\
\hline Concrete experience earning style & $30 / 20$ & $4 / 65$ & 46 & 16 \\
\hline Reflective observation learning style & $31 / 53$ & $5 / 43$ & 48 & 15 \\
\hline Abstract conceptualization learning style & $31 / 83$ & $6 / 24$ & 48 & 14 \\
\hline Active experimentation learning style & $132 / 46$ & $13 / 64$ & 18 & 102 \\
\hline Total creativity score & $47 / 49$ & $5 / 64$ & 66 & 28 \\
\hline Fluidity subtest & $22 / 42$ & $3 / 44$ & 33 & 14 \\
\hline Extension subtest & $35 / 20$ & $5 / 05$ & 48 & 25 \\
\hline Initiative subtest & $25 / 35$ & $3 / 43$ & 33 & 14 \\
\hline Flexibility subtest & &
\end{tabular}

The zero-order correlation matrix of the research variables are provided in table (2). 
Table 2. Correlation matrix of the research variables

\begin{tabular}{|c|c|c|c|c|c|c|c|}
\hline Row & Variables & 1 & 2 & 3 & 4 & 5 & 6 \\
\hline 1 & Locus of control & - & & & & & \\
\hline 2 & Divergent learning style & $0 / 11^{*}$ & - & & & & \\
\hline 3 & Convergent learning style & $-0 / 20^{* *}$ & $-0 / 65^{* *}$ & - & & & \\
\hline 4 & Assimilator learning style & $-0 / 94$ & $0 / 13^{*}$ & $0 / 29^{* *}$ & - & & \\
\hline 5 & Accommodator learning style & $-0 / 01$ & $0 / 24^{* *}$ & $0 / 14^{*}$ & $-0 / 52^{* *}$ & - & \\
\hline 6 & Creativity & $0 / 17^{*}$ & $-0 / 20^{* *}$ & $0 / 29^{* *}$ & $0 / 15^{* *}$ & $-0 / 04$ & - \\
\hline \multicolumn{7}{|c|}{ Significance at the $0 / 01$ level** } \\
\hline
\end{tabular}

Table3. Test of multivariate variance analysis (MANOVA) for comparing the students with internal and external locus of control in terms of learning styles

\begin{tabular}{|c|c|c|c|c|c|}
\hline Locus of control & Value & $\mathrm{F}$ & Hypothesis freedom degree & Error freedom degree & Sig. \\
\hline Pillai's effect & $0 / 32$ & $3 / 23$ & $3 / 00$ & $296 / 000$ & $0 / 03$ \\
\hline Wilks' lambda & $0 / 968$ & $3 / 23$ & $3 / 00$ & $296 / 000$ & $0 / 03$ \\
\hline Hetling effect & $0 / 033$ & $3 / 023$ & $3 / 00$ & $296 / 000$ & $0 / 03$ \\
\hline Roy's largest root & $0 / 033$ & $3 / 23$ & $3 / 00$ & $296 / 000$ & $0 / 03$ \\
\hline
\end{tabular}

As indicated in table (3), all the tests of the multivariate variance analysis (MANOVA)are significant at the $(\mathrm{P}<0 / 03)$ level, meaning at east there is a difference in one of learning styles among the students with internal and external locus of control. As a result, the research hypothesis is confirmed.

Table 4. One-way variance analysis test (ANOA) in the ANOVA context for investigating differences in learning styles among the students with internal and external locus of control

\begin{tabular}{|c|c|c|c|c|c|c|}
\hline $\begin{array}{c}\text { Independent } \\
\text { variable }\end{array}$ & Dependent variable & $\begin{array}{c}\text { Square } \\
\text { sum }\end{array}$ & Freedom degree & $\begin{array}{c}\text { Average } \\
\text { square }\end{array}$ & F & Sig. \\
\hline \multirow{4}{*}{$\begin{array}{c}\text { Locus of } \\
\text { control }\end{array}$} & $\begin{array}{c}\text { Divergent learning } \\
\text { style }\end{array}$ & $94 / 917$ & 1 & $94 / 917$ & $1 / 524$ & $0 / 218$ \\
\cline { 2 - 7 } & $\begin{array}{c}\text { Convergent } \\
\text { learning style }\end{array}$ & $563 / 405$ & 1 & $563 / 405$ & $8 / 721$ & $0 / 003$ \\
\cline { 2 - 7 } & $\begin{array}{c}\text { Assimilator } \\
\text { learning style }\end{array}$ & $126 / 709$ & 1 & $126 / 709$ & $2 / 643$ & $0 / 105$ \\
\cline { 2 - 7 } & $\begin{array}{c}\text { Accommodator } \\
\text { learning style }\end{array}$ & $7 / 492$ & 1 & $7 / 492$ & $0 / 164$ & $0 / 685$ \\
\hline
\end{tabular}

According to table (4), only the convergent learning style among the students with internal and external locus of control significant at the 0/003, other learning styles have no significant difference in the students with internal and external students

Table 5. Independent group's t test

\begin{tabular}{|c|c|c|c|c|}
\hline \multicolumn{2}{|c|}{ Levene's test for the homogeneity of the variances } & \multicolumn{3}{|c|}{ Independent groups t test } \\
\hline F & Sig. & $\mathrm{t}$ & $\begin{array}{c}\text { Freedom } \\
\text { degree }\end{array}$ & Sig (2-tailed) \\
\hline \multirow{2}{*}{$0 / 005$} & $0 / 944$ & $-0 / 979$ & 298 & $0 / 328$ \\
& $-0 / 979$ & $297 / 53$ & $0 / 328$ \\
\hline
\end{tabular}


As indicated in table (5), there is not a significant difference in the students with internal and external locus of control in terms of creativity

Table 6. One-way variance analysis test (ANOA) for investigating differences in learning styles among the students with various learning styles in terms of creativity

\begin{tabular}{|c|c|c|c|c|c|}
\hline Source of changes & Square sum & Freedom degrees & Average square & $\mathrm{F}$ & Sig. \\
\hline Inter group variance & $327 / 92$ & 3 & $1092 / 30$ & $6 / 17$ & $0 / 001$ \\
\hline Within group variance & $52381 / 86$ & 296 & $176 / 96$ & - & - \\
\hline Total variance & $55658 / 79$ & 299 & - & - & - \\
\hline
\end{tabular}

Table (6), Indicates there is a significant difference among the students with various learning styles in terms of creativity at the $0 / 001$ level and for investigating differences closer the Scheffe follow up test has been used where the results are presented in table, 7.

Table 7. Scheffe test results between learning styles in the creativity score

\begin{tabular}{|r|c|c|c|c|c|c|}
\hline $\begin{array}{r}\text { Dependent } \\
\text { variable }\end{array}$ & Average & Learning styles & Divergent & Convergent & Assimilator & Accommodator \\
\hline $\begin{array}{r}\text { Statistical } \\
\text { index }\end{array}$ & & & & & & \\
\hline \multirow{4}{*}{ Creativity } & $1 / 26$ & Divergent & - & $*$ & - & - \\
\cline { 2 - 8 } & $1 / 36$ & Convergent & $*$ & - & - & - \\
\cline { 2 - 8 } & $1 / 31$ & Assimilator & - & - & - & - \\
\cline { 2 - 8 } & $1 / 31$ & Accommodator & - & - & - & - \\
\hline
\end{tabular}

Significance at the $0 / 05$ level *

There is only a significant difference only in convergent and divergent learning styles in terms of creativity

\section{Conclusion}

The current paper aimed to investigate the relationship of locus of control and creativity with learning styles where the results indicated there is a difference among the students with internal and external locus of control in terms of learning styles. These results are in line with the Dashti (2006) research. Rogers (1995) has introduced one of the cognitive styles as "the internal locus of control versus the external locus of control"(Quoted by Dashti, 2006), and it is one of the cognitive styles of learning style (Quoted by Seif, 2008). Therefore, the locus of control and learning style are both influenced by the cognitive style (Both have roots in cognitive styles) which are determined by some environmental and social factors (Abdullah, 1989; Lefkort, Martin, 1985; quoted by Hatami et al, 2010). Because the locus of control and learning styles have both roots in cognitive styles and can be acquired, it can be said that culture affects the locus of control and learning styles (including the way people are treated in their families, educational centers and cultural values governing the society) and also given the results of this research that only the convergent learning style is significant among the students with internal and external locus of control and other styles are not significant, hence the students with internal and external locus of control have an active experimentation and abstract conceptualization learning style. These students could be successful in technical, specialized and technological affairs. 
Another explanation about this issue is parents possibly at the very first years of age, due to some cultural poverty (unawareness) and financial problems cannot create a groundwork for creativity and divergent thinking through enriching the life environment like travel, visiting museums and recreational centers for children and leave them free to make decisions. These children are raised in families where the elders (parents) make decisions instead of them. Also, due to the fact that the present paper has been carried out in one of the cultural areas of Iran, province of Kurdistan, city of Kamyaran which has been transformed into a city from a community of immigrants and rural people in a short term and due to parents' lack of awareness, teachers and the education system pay little attention to the students' creativity. Kurdistan has its own special ways of nurturing in which parents provide a suitable ground for a practical use of thoughts and theories upon which solutions are found for the problems. Such people when faced with some problems will struggle to find solutions quickly or try to concentrate their efforts on them. Because they have convergent thinking, hence they follow custom ion their own thoughts and practice.

Also, results indicated that there is no difference among the students with the internal and external locus of control in terms of creativity. The results found do not correspond with those of Boostan (2001), Sheikholeslami et al (2003), Shahraray (1995) and Gohari (1997). Another explanation about this issue is that the concept of locus of control will in fact enhance existing personality differences about our ideas towards our locus of control (Scholts and Scholts , 2008). Therefore, it is a motivational phenomenon. A motivational pattern states that self-service bias arises from our need to maintain and increase self-esteem or from our inclination to look good in the eye of others (Barron et al, 2008; Trans by Karimi, 2010). Another explanation on this issue is that a locus of control learned in childhood and is related directly with parents' conducts, external control opinions are possibly taught in families where they have lacked a role for the adults. Also, external control opinions increase with the number of siblings. Thus, children in the families with single parents who are under the control of mothers will highly likely raise the external locus of control (Scholts and Scholts , 2008, Trans by Seid Mohamadi, 2008).

Also, results indicated that there is a difference among the students with various learning styles and creativity levels. The results are in concert with the Dashti research (2006). They are not in line with results found by Emmaipoor and Shamsesfand Adabadi (2010), Seif (2008). Another explanation on this issue is that the educational structure (teaching) is regarded one of the main dimensions of teachers' performance. Knowledgeable and capable teachers could by exploring methods and creative teaching styles and using learning styles and paying attention to personality characteristics can teach inappropriate material so creatively and create an appropriate atmosphere in the class. Jacobs and Dominowski (1981) and Martinsen (1995) stated students when addressing cognitive issues require applying unusual method of problem solving (Quoted by Husseini, 2006). Another explanation on this issue is that given the Brathon and Vallason (2004), Mitchel and Biatofska (2000) illustrated the students with divergent learning styles have a more significant creativity test score more than other students. Like other researches, this research faced some limitations. This research was conducted on third grade high school students in Kamyaran, hence generalizing the data to other educational levels face limitations. In addition, in this research questionnaire was the only tool for collecting data with self-report process. For this, bias might be involved in the research. 


\section{References}

[1] Abdullah, T. M. (1989). Self esteem and locus of control of college men in Saudi Arabia. Psychogical Reports. 65,1323-1326.

[2] Guilfrod J.p. (1962). Factors that aid and hinder creativty. Teachers College Record, 63 ,380-389.

[3] Hohan, R.L (1995). Classroom learning and teaching. U.S.A, Longman.

[4] Kimble، G.A. (1961). Hilgard and Marquis conditioning and learning (2nd ed.)Englewood Cliffs, NJ: Prentice Hall.

[5] Kolb, D. A. (1984). Experiential learning: Experience as the source of learning and development. Prentice-Hall, Englewood Cliffs, NJ.Available from $\mathrm{htt}: / / \mathrm{www} \cdot$ sciencedirect.com/science.

[6] Rotter. J. B (1966). Generalized Expectancies of In ternal Versus External Control of Reinforcement. Psychological: Monograph: General and Applied, 80(1) Whole. No. 607.

[7] Baron, Robert; Biren , Daden (2008), Psychosociology, Trans by Yousef Karimi, (2010), Tehran: Ravan.

[8] Behjoya, Nazem )(2009), Creativity methods for today's and tomorrow's generation , Tehran ; Rasa press.

[9] Boostan , Afsane, (2002), Investigating the relation of locus of control and creativity among the Sanati Sharif University students , M.A thesis,

[10] Daemi, Hamidreza; Moghimi Barforoush, Seide Fateme (2004), Standardization of creativity test (Ministry of education, bureau of women's' affairs), University of Allame Tabatabaee, Counseling center, Cognitive sciences innovations, No. 3 and 4, 1-8.

[11] Dashti, Mehrdad (2006), Simple and multiple relation of learning styles, creativity and locus of control in students M.A. thesis, University of Shahid Beheshti, Tehran.

[12] Ebrahimibakht, Habiballah (2007), Investigating relationship between personal efficacy, locus of control, and academic achievement of the third grade high students in Humanities, M.A. thesis, Nashde press, Islamic Azad University, Sciences and Research Branch.

[13] Emamipoor, Soozan; Shamsesfand Abadi, Hasan (2000), Studying learning style of unilingual and bilingual students of the junior school level and its relation with educational achievement and gender, Journal of educational innovations, second year, No. 3, 11-28.

[14] Gohari, Moslem,(1996), Investigating the relation of self-concept and locus of control with creativity among the junior school students at public schools in Tehran: M.A. thesis, Educational sciences major.

[15] Hatami, Hamidreza; Mohamadi,. Nahid; Ebrahimi, Mohsen; Hatami, Masoome (2010), Relation of locus of control and personality characteristics, Thoughts and practice, (Applied psychology), fifth period, No. 18, 21-30.

[16] Husseini, Afzalsadat (2006), Pattern of creativity growth and its efficacy in creating teaching skill among the elementary teachers. Quarterly of educational innovations, No.15, fifth year, 177-201. 
[17] Parsa, Mohamad, (2007), Learning psychology based on theories, Tehran: Be'sat press.

[18] Scholts, Dwan; Scholts, Sydney Allen (2008), Theories of personality, Trans by Seid Yahya Mohamadi, (2008), Tehran: Virayesh press.

[19] Seif, Aliakbar (2008), Modern developmental psychology (Psychology of learning and education), Tehran: Doran press.

[20] Shahraray, Mehrnaz (1995), Pattern of creative behavior interaction, educational research, scientific-research quarterly, Research institute of Tarbyat Moallem University, Third Vol, Nos. 3 and 4.

[21] Sheikholeslami, Razie; Razavi, Asghar (2005), Predicting students' creativity at the University of Shiraz in accordance with external motivation variables, internal motivation and gender, Journal of social sciences and Humanities at the University of Shiraz, $22^{\text {nd }}$ period, No. $4^{\text {th }}$, Winter, 94-103.

[22] Solso, Robert, L(2008), Cognitive psychology, Trans by Farhad Mehr (2009), Tehran: Roshd press.

[23] Young LE, Paterson BL.(2007). Teaching Nursing . Philadelphia: Lippincott Williams \& Wilkins; 2007. 